Available online on 15.05.2020 at http://jddtonline.info
Open Access to Pharmaceutical and Medical Research
unrestricted non-commercial use, provided the original work is properly cited

Open $\odot$ Access

Review Article

\title{
Recent trends in management of common glomerulopathy
}

\author{
Kamel El-Reshaid \\ Department of Medicine, Faculty of Medicine, Kuwait University
}

\begin{abstract}
Diagnosis of glomerulopathy requires correlation between: (a) clinicopathological syndromes, (b) kidney histology for the abnormalities which are useful for the severity of disease, stage of activity and extent of chronicity. Subsequently, management dictates the choice of effective medications to avoid renal loss and long-term side effects. In this review article; we provide our practical experience with drug-therapy in common idiopathic and secondary glomerular diseases.
\end{abstract}

Keywords: glomerulopathy, kidney biopsy, nephrotic syndrome, Rituximab, treatment.

Article Info: Received 06 March 2020; Review Completed 22 April 2020; Accepted 29 April 2020; Available online 15 May 2020

Cite this article as:

El-Reshaid K, Recent trends in management of common glomerulopathy, Journal of Drug Delivery and Therapeutics. 2020; 10(3):288-292 http://dx.doi.org/10.22270/jddt.v10i3.4004

*Address for Correspondence:

Dr. Kamel El-Reshaid, Professor, Dept. Of Medicine, Faculty of Medicine, Kuwait University, P O Box 24923, 13110 Safat,

Kuwait

Fax : (965) 5318454 Or E-mail : kamel@hsc.edu.kw

\section{INTRODUCTION}

Glomerulopthy $(\mathrm{G})$ is an injury to the glomerulus. The latter is the first segment of the nephron which is responsible for filtration of blood received from the afferent arteriole and existing via the efferent one. The glomerulus is formed by the branching of the afferent arteriole which loses its muscular wall and left only with a glomerular basement membrane (BM) and an inner lining of endothelial cells. The latter arrangement is to provide an unhindered filtration process (Fig.1). The filtered fluid is collected in the first part of the urinary tubules which is the bowman space formed by an inner visceral and an out parietal layer of the bowman capsule.

\section{MANIFESTATIONS OF G}

$\mathrm{G}$ is a common cause of renal disease with an annual incidence rate 34.5 per 100,000 populations (PTP) [1]. In the latter study 21.1 PTP were non-diabetic G, of whom secondary lesions viz. lupus nephritis and vasculitis shared 4.8 PTP. G manifests as proteinuria caused by altered permeability of the BM, hematuria if BM ruptures, oliguria if reduced filtration of fluids leading to fluid overload, oedema and hypertension and lastly azotemia if impaired filtration of nitrogenous end-products of catabolism. The prognosis of $\mathrm{G}$ depends on nature of disease and its severity.

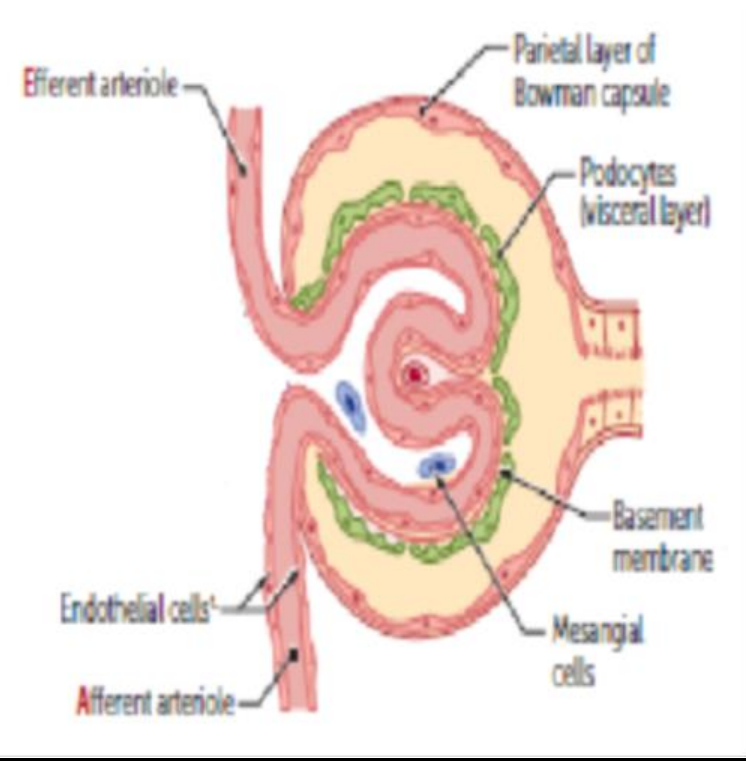

Figure 1: Showing ultrastructural features of normal glomerulus 


\section{DIAGNOSIS OF G}

It requires recognition of: (a) clinicopathological syndromes, (b) kidney histology for the abnormalities which are useful for the severity of disease, stage of activity and extent of chronicity. The clinicopathological abnormalities includes; clinical manifestations, routine laboratory tests and serological markers of disease. The latter serum tests include; complements (C3 \& C4), ANA, anti-dsDNA, ANCA, anti-GBM antibodies, IgA level, SPEP, HBsAg and hepatitis C antibodies. Finally; the correlation between both is essential for final diagnosis. Kidney biopsy establishes the histological type and guides selection of its specific therapy of since some G are steroid-refractory. The next step is to assess if the histological diagnosis fits with the clinicopathological syndromes i.e. clinicopathological correlation since: (a) some histological diagnosis are secondary to systemic diseases, (b) superimposed G have been reported. An example of the latter is a case of acute nephrotic syndrome (NS) in a diabetic glomerulosclerosis (DGS) or an IgA histological features; can't rule out minimal change disease (MCD) superimposed on those G. Diagnosis of the latter may prove to be difficult even with the aid of electron microscopy to evaluate ultrastructual deposits and BM changes and an empiric trial of short-course of Prednisone may confirm diagnosis.

\section{CLINICOPATHOLOGICAL SYNDROMES}

Those with their corresponding histological lesions are summarized in Table 1. They include 4 clinical syndromes; (a) NS characterized by history of oedema and proteinuria $\geq$ $3.5 \mathrm{~g} /$ day, (b) advanced NS (with renal impairment) i.e. all diseases in the first group except pure MCD, (c) acute renal failure with hematuria and proteinuria which includes patients with proliferative and crescentic glomerular lesions, (d) asymptomatic hematuria with/without hematuria and renal impairment accidently disclosed during routine work up.

\section{MECHANISMS OF G}

1- MCD: The initial event starts by activation of Tlymphocyte leading to stimulation of B-lymphocyte to liberate a permeability factor [2]. The latter abolishes the negative charge on glomerular BM. Serum albumin is a negatively-charged small molecule that can easily pass through the fenestra of the BM yet is normally repelled by the negative charge on BM. Interestingly, such phenomenon prevents the attachment of the visceral layer of bowman capsule on the epithelial (outer) side of BM leading to a foot-process structure. Once the negative charge is lost; albumin can passes freely through the fenestra of BM and the visceral cells spread on the BM losing the foot-processes shape. Since the defect is loss of negative charge of BM rather than an inflammatory process; MCD is not associated with glomerulosclerosis. The initiating factor from $\mathrm{T}$ lymphocyte is interleukins which can be blocked by Calcineurin inhibitors (CNI) and activated mature Blymphocyte can be targeted with Rituximab $[3,4]$.

2- Certain immune complexes (IC) are bland and do not generate inflammatory response such as idiopathic membranous G (MG). Hence; treatment is only if severe NS and evidence of glomerulosclerosis [5]. Since deposits; with Rituximab therapy, improvement in MG may need 2 months compared to only few days in MCD since the latter is an electrical defect [6].

3- Slow deposition of IC may be associated with mild inflammation leading to mild $G$ with limited glomerulosclerosis such as IgA nephropathy [7]. However, in genetically predisposed patients, highload of such IC leads to abnormal mesangial cells reaction with subsequent progressive glomerulosclerosis and kidney loss. The $\mathrm{G}$ is the most common G in Far East and South East Asia and Europe and accounts for $25 \%$ of G. Since not a florid inflammation; such phenotype rarely benefits from chronic immunosuppression [8].

4- Idiopathic focal and segmental glomerulosclerosis (FSGS) is induced by a mixture of another form of permeability factor and IC disease [9]. The IC is IgM and starts segmentally leading to progressive sclerosis and subsequent hyperfiltration, hypertension and progressive G. If treated early; its acute NS can improve. However, it needs long-term maintenance therapy and if untreated; $50 \%$ can progress to endstage kidney disease within 5 years [10].

5- Inflammatory lesions are initiated by antigens. Some are short-lived such as post-streptococcal glomerulonephritis or clear after treatment of infections such as post-infectious and membranoproliferative ones $[11,12]$. However, highload deposits as in lupus nephritis can initiate severe inflammatory response with endothelial cell proliferation, necrosis and rupture of BM leading to crescent formation by activation of podocytes of the visceral layer of bowman capsule [13]. Hence, an according to genetic predisposition, lupus nephritis can present as membranous G, proliferative G and IC crescentic G. The disease needs aggressive immunosuppressive therapy to stop the active process (induction phase) followed by an effective and safe long-term maintenance immunosuppressive treatment to prevent its relapse [14]. Vasculitis is another severe systemic vascular autoimmune disease [15]. Involvement of medium-sized vessels, in polyarteritis nodosa, leads to kidney infarctions and stripped fibrotic renal loss. Small-vessel disease can lead to glomerular BM damage with necrotizing $G$ and/or crescentic one if vessel ruptures leading to podocyte disease. The latter presentation is common in Wegner's granulomatosis, microscopic polangiitis and anti-glomerular BM disease.

\section{TREATMENT OF COMMON GLOMERULAR DISEASES:}

Management of common glomerulopathy is summarized in table 2. Certain issues should be respected:

1- Nearly $90 \%$ of NS in children is due to steroidresponsive MCD. In adult population; the prevalence falls to $20 \%$ with nearly $40 \%$ are due to MG which is steroid-refractory G [16]. Hence, kidney biopsy; should be done in any adult with NS except for typical DGS.

2- The prevalence of DGS is 50\% in type I DM and $20 \%$ in type II DM. The classic presentation of DGS is with 4 signs; slowly progressive NS, > 5 years after type II or > 10 years in type I, normal-sized kidneys and proliferative retinopathy. The latter findings should be associated with negative clinical, laboratory and serological markers of autoimmune diseases. Since type II DM is common and DGS is prevalent in $20 \%$ of those diabetics; kidney biopsy is rarely done if presentation is typical [17]. However, unexplained acute renal and sudden NS in an already accepted DGS 
3- Clinically indicates kidney biopsy to rule out superimposed lesions or an initial misdiagnosis [18].

4- In rapidly progressive G; aggressive immunosuppressive induction therapy should be initiated till the final histopathological diagnosis is available.

5- Overall, immunosuppressive drugs should be efficacious and with minimal long-term side effects. Rituximab, if financially accessible, is preferred to longterm Corticosteroids, Alkylating agents and even $\mathrm{CNI}$ [6]. The latter drugs are efficacious alone or in combination with others in some cases of FSGS. However, caution should be exercised on long-term treatment and with doses $>3 \mathrm{mg} / \mathrm{kg}$ to avoid interstitial fibrosis [19].

\section{REFERENCES:}

1- El-Reshaid W, El-Reshaid K, Kapoor MM, Madda JP. Glomerulopathy in Kuwait: The spectrum over the past 7 years. Renal failure 2003; 25:619-630.

2- Lagrue G, Xheneumont S, Branellec A, Hirbec G, Weil B. A vascular permeability factor elaborated from lymphocytes. I. Demonstration in patients with nephrotic syndrome. Biomedicine 1975; 23:37-40.

3- El-Reshaid K, Amer E, Madda JP, Kapoor MM. Long-term cyclosporin A (Cy A) treatment in adults with refractory nephrotic syndrome. Renal Failure (USA) 1995; 17: 695-703.

4- Kimby E. Tolerability and safety of rituximab (MabThera). Cancer Treat Rev 2005; 31:456-473.

5- Waldman M, Austin HA. Treatment of idiopathic membranous nephropathy. JASN 2012; 23:1617-1630.

6- Kamel El-Reshaid, Hossam Eldin Tawfik Salla, Abass Ali Hakim, Raja Al-Atiyaa. Rituximab in treatment of idiopathic glomerulopathy. Saudi Journal of kidney diseases and transplantation 2012; 23:973-978.

7- Magistroni R. New development in the genetics, pathogensis, and therapy of IgA nephropathy. Kidney Int 2015; 88:974989.

8- Strippoli GF, Manno C, Schena FP. An "evidence-based" survey of therapeutic options for IgA nephropathy: assessment and criticism. Am. J. Kidney Dis 2003; 41:1129-1139
9- Kumar V, Fausto N, Abbas A, eds. (2003). Robbins \& Cotran Pathologic Basis of Disease (7th ed.). Saunders. pp: 982-983.

10- U.S. Renal Data System, USRDS 1998 Annual Data Report. National Institute of Health, National Institute of Diabetes and Digestive and Kidney Diseases. Bethesda, MD, April 1998; 23 35.

11- Rodríguez-Iturbe, B, Batsford, S. Pathogenesis of poststreptococcal glomerulonephritis a century after Clemens von Pirquet. Kidney Int 2007; 71:1094-1104.

12- Sethi S, Fervenza FC. Membranoproliferative glomerulonephritis: pathogenetic heterogeneity and proposal for a new classification. Semin Nephrol 2011; 31:341-348.

13- Weening JJ, D'Agati VD, Schwartz MM, et al. The classification of glomerulonephritis in systemic lupus erythematosis revisited. J Am Soc Nephrol 2004; 15:241-250.

14- Kamel El-Reshaid, Wael El-Reshaid, Shaikha Al-Bader, Hossameldin Tawfik Sallam, Abbass Ali Hakim, Rajaa AlAttiyah. New protocols for treatment of class IV lupus nephritis with emphasis on Rituximab as the sole maintenance therapy. Kuwait Medical Journal 2018; 50:343350.

15- El-Reshaid K, Kapoor MM, El-Reshaid W, Madda JP, Varro J. The spectrum of renal disease associated with microscopic polyangiitis and classic polyarteritis nodosa in Kuwait. Nephrol Dial Transplant 1997; 12: 1874-1882.

16- Chen Y, Schieppati A, Chen X, Cai G, Zamora J, et al. (October 2014). Immunosuppressive treatment for idiopathic membranous nephropathy in adults with nephrotic syndrome. The Cochrane Database of Systemic Reviews (10): CD004293.

17- Biesenbach G, Bodlaj G, Pieringer H, Sedlak M. Clinical versus histological diagnosis of diabetic nephropathy - is renal biopsy required in type 2 diabetic patients with renal disease? QJM 2011; 104:771-774.

18- Mak SK, Gwi E, Chan KW et al. Clinical predictors of nondiabetic renal disease in patients with non-insulin dependent diabetes mellitus. Nephrol Dial Transplant 1997; 12:25882591.

19- Nankivell BJ, P'Ng CH, O'Connell PJ, Chapman JR. Calcineurin Inhibitor Nephrotoxicity through the Lens of Longitudinal Histology: Comparison of Cyclosporine and Tacrolimus Eras. Transplantation 2016; 100:1723-1731. 
Table 1: Clinicopathological syndromes of common glomerulopathies

Nephrotic

(oedema + proteinuria $\geq 3.5 \mathrm{~g} /$ day)
Advanced nephrotic

Nephritic

(ARF+Proteiuria)
Asymptomatic hematuria

( \pm proteinuria) $\underline{1-\text { Minimal change disease }}$
a- Primary
b- Secondary: Hodgkin, Leukemia

2-Membranous glomerulopathy

a- Primary

b- Solid cancers, drugs (d-PNC, gold), SLE, infections

3-Focal segmental glomerulosclerosis

a- Primary

b- Secondary: genetic, HIV, hyperfiltration, obesity, drugs

4-Membranoproliferative:

a- Rarely idiopathic (causes: infections including: Hepatitis $\mathrm{C} \pm$ Cryoglobulinemia)

b- C3 glomerulopathy

5- Fibrillary/immunotactoid

6- Nodular glomerulosclerosis:

Diabetic GS

Amyloidosis/Light chain

\section{Proliferative}

All NS except

pure MCD

1- Post-infectious/strept

2- Lupus nephritis

\section{Crescentic}

1- Anti-GBM disease 1- IgA nephropathy

2- Immuncomplex mediated 2- Thin membrane disease

3- Pauci-immune deposits/vasculitis
3- Alport's syndrome 
Table 2. Immunosuppressive treatment of common primary glomerulopathy

A- Minimal change disease:

I- Steroid-responsive:

1- No further relapse $(10 \%)$

2- Infrequent relapser (30\%)

3- Frequent relapser/steroid-dependent (50\%):

II- Steroid-resistant (10\%):

B- Membranous glomerulopathy:

1- Induction:

2- Maintenance:

C- Focal segmental glomerulosclerosis:

$$
\text { 1- Induction: }
$$

2- Maintenance:

D- MPGN

1- Treat underlying infection:

2- C3-glomerulopathy:

E- Diabetic glomerulosclerosis:

F-Amyloidosis/Light chain:

G- Lupus nephritis (stage3 \& 4 \& NS with membranous):

$$
\text { 1- Induction phase (3 months): }
$$

2- Maintenance phase:

H-Vasculitis/Crescentic glomerulopathy:

1- Induction phase (3 months):

2- Maintenance phase (2 years):

N.B.: if anti-GBM vasculitis: plasma exchange should be added
Prednisone for 3 months

None

Repeat Prednisone course*

C-IH + MMP for 1 year or yearly Rituximab (1-4 years)

$\mathrm{Rx}$ as FSGS

$\mathrm{C}-\mathrm{IH}+\mathrm{MMP}$

yearly Rituximab for 4-5 years

C-IH + MMP

Yearly Rituximab $\pm \mathrm{C}-\mathrm{IH} \pm \mathrm{MMP}$

1- If hepatitis + Cryglobulinemia: Solvady + yearly Rituximab (if NS)

2- No specific immunosuppressive Rx

Control hyperglycemia \& ACEI/ARB (control hypertension and

hyperfiltration): slows the disease

Treat the cause \& if MM or Light chain: chemotherapy

Combination of 3 agents: Steroid ${ }^{* *}+$ MMP + IV cyclophosphamide

Rituximab yearly infusions or Prednisone $5 \mathrm{mg} /$ day + MMP

Combination of 3 agents: Steroid ${ }^{* *}+$ MMP + IV cyclophosphamide

Rituximab yearly infusions or Prednisone $5 \mathrm{mg} /$ day + MMP

\section{Abbreviations \& dosage of medications:}

* Prednisone $2 \mathrm{mg} / \mathrm{kg} /$ day ( $<60 \mathrm{mg} / \mathrm{m} 2$ ) for 4 weeks then taper down gradually till discontinuation by $3 \mathrm{rd}$ month

** $1 \mathrm{~g}$ of Solumedrol IV daily for 3 days followed by Prednisone $2 \mathrm{mg} / \mathrm{kg} /$ day (not $>60 \mathrm{mg} /$ day) foe 4 weeks then to be tapered down till $5 \mathrm{mg} /$ day

MMP: Mycophenolate mofetil; dose: $600 \mathrm{mg} / \mathrm{m} 2$ orally 2 times a day up to a maximum of 2 grams per day

Cyclophosphamide $750 \mathrm{mg} / \mathrm{m} 2 \mathrm{IV}$ monthly infusions in $200 \mathrm{ml}$ of normal saline over 2 hours

C-IH: Calcineurin inhibitors:

A- Tacrolimus (Prograf): $0.1 \mathrm{mg} / \mathrm{kg} /$ day up to $2 \mathrm{mg}$ twice daily

B- Cyclosporine A (Neoral): $5 \mathrm{mg} / \mathrm{kg} /$ day up to $100 \mathrm{mg}$ twice daily 